\title{
Increases in microvascular perfusion and tissue oxygenation via pulsed electromagnetic fields in the healthy rat brain
}

\author{
Denis E. Bragin, PhD, ${ }^{1,2}$ Gloria L. Statom, MSBME, ${ }^{1}$ Sean Hagberg, $\mathrm{PhD},{ }^{3}$ \\ and Edwin M. Nemoto, PhD'
}

1Department of Neurosurgery and ${ }^{2}$ Biomedical Research and Integrative Neuroimaging Center, University of New Mexico, Albuquerque, New Mexico; and ${ }^{3} / v i v i$ Health Sciences, San Francisco, California

\begin{abstract}
OBJECT High-frequency pulsed electromagnetic field stimulation is an emerging noninvasive therapy being used clinically to facilitate bone and cutaneous wound healing. Although the mechanisms of action of pulsed electromagnetic fields (PEMF) are unknown, some studies suggest that its effects are mediated by increased nitric oxide (NO), a well-known vasodilator. The authors hypothesized that in the brain, PEMF increase NO, which induces vasodilation, enhances microvascular perfusion and tissue oxygenation, and may be a useful adjunct therapy in stroke and traumatic brain injury. To test this hypothesis, they studied the effect of PEMF on a healthy rat brain with and without NO synthase (NOS) inhibition.
\end{abstract}

METHODS In vivo two-photon laser scanning microscopy (2PLSM) was used on the parietal cortex of rat brains to measure microvascular tone and red blood cell (RBC) flow velocity in microvessels with diameters ranging from 3 to 50 $\mu \mathrm{m}$, which includes capillaries, arterioles, and venules. Tissue oxygenation (reduced nicotinamide adenine dinucleotide [NADH] fluorescence) was also measured before and for 3 hours after PEMF treatment using the FDA-cleared SofPulse device (Ivivi Health Sciences, LLC). To test NO involvement, the NOS inhibitor $N^{G}$-nitro-L-arginine methyl ester (L-NAME) was intravenously injected $(10 \mathrm{mg} / \mathrm{kg}$ ). In a time control group, PEMF were not used. Doppler flux (0.8-mm probe diameter), brain and rectal temperatures, arterial blood pressure, blood gases, hematocrit, and electrolytes were monitored.

RESULTS Pulsed electromagnetic field stimulation significantly dilated cerebral arterioles from a baseline average diameter of $26.4 \pm 0.84 \mu \mathrm{m}$ to $29.1 \pm 0.91 \mu \mathrm{m}$ (11 rats, $p<0.01$ ). Increased blood volume flow through dilated arterioles enhanced capillary flow with an average increase in RBC flow velocity by $5.5 \% \pm 1.3 \%(p<0.01)$. Enhanced microvascular flow increased tissue oxygenation as reflected by a decrease in NADH autofluorescence to $94.7 \% \pm 1.6 \%$ of baseline $(p<0.05)$. Nitric oxide synthase inhibition by L-NAME prevented PEMF-induced changes in arteriolar diameter, microvascular perfusion, and tissue oxygenation (7 rats). No changes in measured parameters were observed throughout the study in the untreated time controls (5 rats).

CONCLUSIONS This is the first demonstration of the acute effects of PEMF on cerebral cortical microvascular perfusion and metabolism. Thirty minutes of PEMF treatment induced cerebral arteriolar dilation leading to an increase in microvascular blood flow and tissue oxygenation that persisted for at least 3 hours. The effects of PEMF were mediated by NO, as we have shown in NOS inhibition experiments. These results suggest that PEMF may be an effective treatment for patients after traumatic or ischemic brain injury. Studies on the effect of PEMF on the injured brain are in progress.

http://thejns.org/doi/abs/10.3171/2014.8.JNS132083

KEY WORDS pulsed electromagnetic field; cerebrovascular flow; brain metabolism; two-photon laser scanning microscopy; $\mathrm{NADH}$; vasodilation

"E LECTROCEUTICALS" for the treatment of brain disorders have recently caught the attention of pharmaceutical companies..$^{10}$ Among the various emerging electrotherapies is high-frequency pulsed electromagnetic field stimulation allowing noninvasive treatment of tissue without heat. ${ }^{44}$ Pulsed electromagnetic field (PEMF) therapy is cleared by the FDA for clinically treating postoperative pain and edema and approved by

ABBREVIATIONS L-NAME = NG-nitro-L-arginine methyl ester; NADH = nicotinamide adenine dinucleotide; NO = nitric oxide; NOS = NO synthase; PEMF = pulsed electromagnetic field(s); RBC = red blood cell; 2 PLSM = two-photon laser scanning microscopy.

SUBMITTED October 2, 2013. ACCEPTED August 29, 2014.

INCLUDE WHEN CITING Published online October 24, 2014; DOI: 10.3171/2014.8.JNS132083.

DISCLOSURE The authors report no conflict of interest concerning the materials or methods used in this study or the findings specified in this paper. Dr. Hagberg has direct stock ownership in Rio Grande Neurosciences. This research was supported by Ivivi Health Sciences, LLC, and American Heart Association grant 12BGIA11730011. 
Medicare for the treatment of chronic wounds. Other clinical indications include bone fractures, ${ }^{1,12}$ soft-tissue injuries, ${ }^{2}$ postsurgical pain, ${ }^{18,35,47}$ and inflammation-induced edema. ${ }^{40}$ In animals, PEMF induce small electrical currents in tissue, promoting endothelial cell growth, ${ }^{38}$ neovascularization, ${ }^{55}$ and wound healing, ${ }^{31}$ and improve angiogenesis in myocardial infarction. ${ }^{60}$

More recently, PEMF have been suggested for use in clinical neurology and rehabilitation. Pulsed electromagnetic field treatment decreased infarct size after transient focal ischemia in rabbits ${ }^{14}$ and after permanent focal ischemia in mice. ${ }^{39}$ The antiinflammatory effects of PEMF have been demonstrated after traumatic brain injury in rats $^{45}$ and after permanent focal ischemia in mice. ${ }^{39} \mathrm{Sev}$ eral studies showed that PEMF improve the rate of peripheral nerve regeneration, ${ }^{22,25,52}$ while another study documented delayed histological peripheral nerve regeneration without loss of functional recovery. ${ }^{5}$ Beneficial effects on visual memory in Alzheimer's patients ${ }^{48}$ and on motor function in Parkinson's patients ${ }^{49}$ have been noted for PEMF treatment as well.

The mechanisms of action of PEMF are not clearly elucidated. One of the suggested targets of PEMF is the microvascular circulation, but existing data are limited, controversial, and incomplete. ${ }^{30}$ Intravital microscopy showed that PEMF dilate arterioles in the web of the frog $^{32}$ and in the cremaster muscle of rats, ${ }^{53}$ but the effects on blood flow remained uninvestigated given the limitations of the method used. Human studies using laser Doppler produced controversial results: blood flow increased in the cutaneous tissues of the $\mathrm{arm}^{27}$ and in peri-ulcer cutaneous tissue, ${ }^{11,28}$ but there was no effect on blood flow in the cutaneous tissues of the foot ${ }^{50}$ and a decrease in the cutaneous tissue of the fingertip. ${ }^{57}$ Similar controversies are found in animal studies performed with Doppler: PEMF increased blood flow in the hind limbs of diabetic rats $^{37}$ but not in the extensor digitorum longus muscle of a healthy rat. ${ }^{29}$ The differences in the microcirculatory effects of PEMF may be attributable to the different PEMF treatment parameters used by investigators. Part of the discrepancy in findings is the result of the heterogeneity of the PEMF signal characteristics, which vary widely. ${ }^{43}$ Despite extensive studies on the peripheral circulation, studies have not focused on the PEMF's effects on the circulation of the brain, which is important because of its tight flow-metabolism coupling.

Importantly, the effects of PEMF on the microcirculation appear to be modulated by nitric oxide (NO), but a direct link between the two has never been established in vivo in neuronal systems. Some studies show that PEMF increase NO synthesis in proliferating osteoblasts, ${ }^{9}$ neuronal culture, human fibroblasts,${ }^{42}$ as well as homogenized rat cerebellum and are mediated by the constitutive NO pathway. ${ }^{33,36}$ Conversely, decreased $\mathrm{NO}^{3}$ or no effect ${ }^{25}$ was shown in other studies on rats. Nevertheless, NO is a wellknown vasodilator and has been suggested as a mediator of PEMF's effects on the microvasculature. ${ }^{41}$

Our aim in this study was to determine, using in vivo two-photon laser scanning microscopy (2PLSM), whether PEMF treatment has any measurable effects on microvascular perfusion and oxygenation in the healthy rat brain.
We tested the hypothesis that PEMF treatment effects on the brain microcirculation are mediated by $\mathrm{NO}$ by $N^{\mathrm{G}}$-nitro-L-arginine methyl ester (L-NAME) inhibition of NO synthase (NOS). In this study we used the FDA-cleared PEMF Sofpulse device (Ivivi Health Sciences), which has been proved effective in reducing pain in breast reduction, ${ }^{47}$ reconstruction, ${ }^{18}$ and osteoarthritis. ${ }^{35}$

\section{Methods}

\section{Animals and Surgical Procedures}

The institutional animal care and use committee of the University of New Mexico Health Sciences Center approved the protocol for these studies, which were conducted according to the National Institutes of Health Guide for the Care and Use of Laboratory Animals. Male Sprague-Dawley rats (23; Harlan Laboratories) weighing $300-350 \mathrm{~g}$ were laboratory acclimated for 1 week. The surgical procedures were as previously described.${ }^{6,7}$ Brief$1 y$, the rats were anesthetized in a box insufflated with $4 \%$ isoflurane $/ 70 \%$ nitrous oxide and $30 \%$ oxygen, intubated with a $14 \mathrm{G} \times 1.9$ " catheter (Angiocath, BD Medical), and mechanically ventilated (model 683, Harvard Apparatus) on $2 \%$ isoflurane $/ 30 \%$ oxygen $/ 70 \%$ nitrous oxide, tidal volume of $2.0-2.5 \mathrm{ml}$ at a respiratory rate of $55-65 / \mathrm{min}$ ute. Atropine ( $0.2 \mathrm{mg}$, intraperitoneal) was administered to reduce mucous secretions. Femoral artery catheters (PE-50) were used to monitor arterial blood pressure and sample blood ( $0.1 \mathrm{ml}$ each). Femoral vein catheters (PE50) were inserted for fluid replacement (lactated Ringers, $1 \mathrm{ml} / \mathrm{hr}$ ), L-NAME administration, and dye injection. Rats were placed in a custom-made nonmagnetic plastic stereotactic head frame specifically designed to avoid interference with the electromagnetic field produced by the SofPulse device (Machine and Electronics Shops, Department of Physics and Astronomy, University of New Mexico). For imaging, a craniotomy $5 \mathrm{~mm}$ in diameter was made over the left parietal cortex $1 \mathrm{~mm}$ lateral to the sagittal suture and $1 \mathrm{~mm}$ posterior to the lambdoidal suture without traumatizing the brain. The craniotomy was filled with $2 \%$ agarose gel in saline, and a cover glass was placed over the craniotomy and glued and sealed onto the skull (cyanoacrylate glue). A cranial temperature probe (1-mm diameter) was inserted into the temporal muscle adjacent to the skull to estimate brain temperature, which was controlled by an overhead infrared lamp. Body temperature was monitored using a rectal probe and was kept at $37.5^{\circ} \mathrm{C}-38.5^{\circ} \mathrm{C}$ with a heating pad throughout the study.

\section{Experimental Paradigm}

The animals were studied in three groups: 1) time control group, 5 rats; 2) PEMF group, 11 rats; and 3) L-NAME group, with L-NAME plus PEMF, 7 rats. In the PEMF group, physiological variables were measured before (two 30-minute imaging sessions with a 30-minute interval between sessions) and after (three 30-minute imaging sessions with a 30-minute interval) 30 minutes of PEMF (Fig. 1). Pulsed electromagnetic field stimulation was induced in the brain by the SofPulse device. Measurements in the time control group were obtained at the same time 


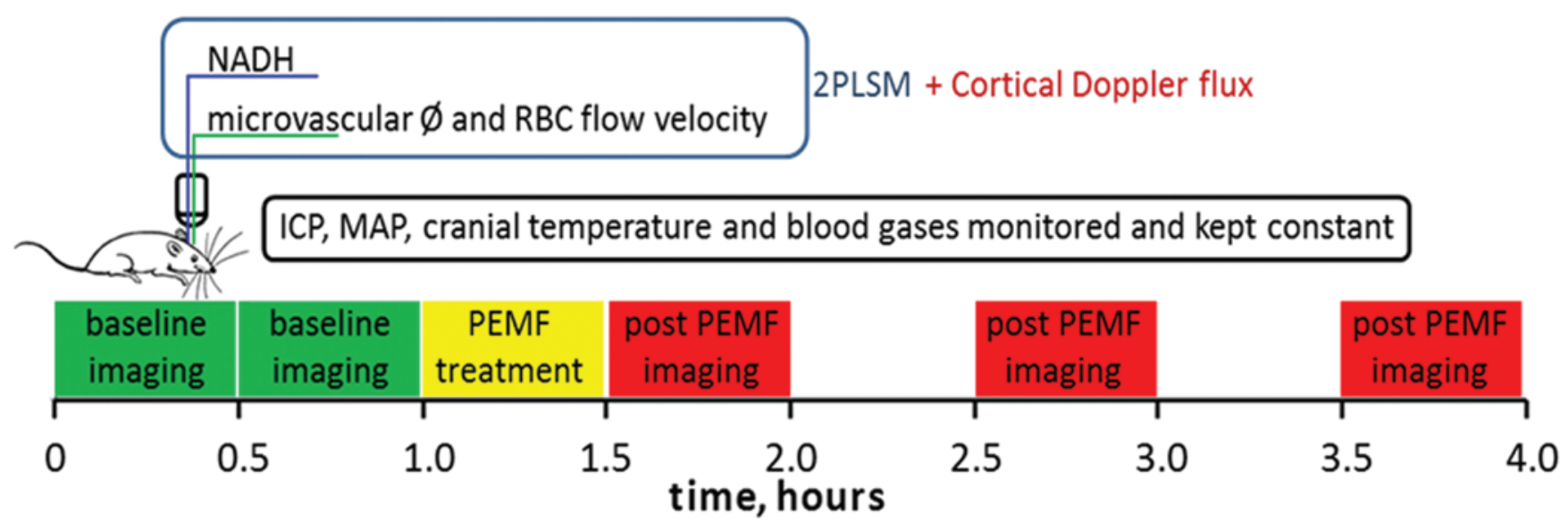

FIG. 1. Experimental paradigm. Figure is available in color online only.

intervals as in the PEMF group. In the L-NAME group, L-NAME was intravenously administered $(10 \mathrm{mg} / \mathrm{kg})$ for NOS inhibition after baseline imaging. Thirty minutes thereafter, baseline imaging was repeated, PEMF were applied, and three imaging sessions were performed with 30-minute intervals between each session.

The PEMF signal was a 27.12-MHz carrier modulated by a 3 -msec burst repeating at $5 \mathrm{~Hz}$ (Fig. 2A). The signal amplitude was adjusted to provide $6 \pm 1 \mathrm{~V} / \mathrm{m}$ within the rat brain. Pulsed electromagnetic field characteristics were verified with a calibrated shielded loop probe $1 \mathrm{~cm}$ in diameter (model 100A, Beehive Electronics) connected to a calibrated 100-MHz oscilloscope (model 2012B, Tektronix). Measurement of the PEMF signal distribution in a tissue phantom and in air provided an accurate map of the signal in tissue. These measurements showed that PEMF amplitude dose was uniform to within $\pm 25 \%$. An additional measure in the tissue phantom showed that the specific absorption rate (SAR), a measure of peak radiofrequency power in tissue, was $40 \mathrm{~mW} / \mathrm{kg}$, which is well below the level at which a detectable temperature rise could occur in the tissue target. ${ }^{44}$

We used in vivo 2PLSM through a cranial window over the parietal cortex to measure microvascular red blood cell (RBC) flow velocity, microvessel diameters, and nicotinamide adenine dinucleotide (NADH) autofluorescence for tissue oxygenation. Relative changes in cortical perfusion were continuously monitored by Doppler flux during the study. Arterial pressure was continuously recorded using Biopac preamplifiers and software (Biopac Systems). Arterial blood gases, hematocrit, $\mathrm{pH}$, glucose, and electrolytes were measured hourly by an iSTAT point of care device with a CG8+ cartridge (Abaxis) and maintained within normal limits throughout the study. Variations in blood gases were adjusted by manipulating the rate and volume of the ventilator. Base deficits less than $-5.0 \mathrm{mEq} / \mathrm{L}$ were corrected by slow intravenous infusion of $8.4 \%$ sodium bicarbonate.

\section{In Vivo 2PLSM}

Two-photon laser scanning microscopy was done as previously described ${ }^{6,7}$ with an Olympus BX51WI upright microscope and water-immersion LUMPlan FL/IR
$20 \times / 0.50 \mathrm{~W}$ objective. Excitation was provided by a Prairie View Ultima multiphoton laser scan unit powered by a Millennia Prime 10-W diode laser source pumping a Tsunami Ti:sapphire laser (Spectra-Physics). Images (512 $\times 512$ pixels, $0.15 \mu \mathrm{m} /$ pixel) or line scans were acquired using Prairie View software. A total average power of 30$300 \mathrm{~mW}$ was delivered to the cortex, the higher values to image at greater depths, always using the lowest intensity required for adequate signal-to-noise ratio.

Microvascular RBC flow velocity was measured with tetramethylrhodamine isothiocyanate dextran $(155 \mathrm{kD})$ in physiological saline $(5 \% \mathrm{wt} / \mathrm{vol})$ injected intravenously at an initial serum dye concentration of $150 \mu \mathrm{M}$. Fluorescence was emitted at a center wavelength of $740 \mathrm{~nm}$ and filtered at $550-650 \mathrm{~nm}$. Red blood cell motion was detected from line scans, that is, repetitive scans along the central axis of a microvessel at several depths $(0-300 \mu \mathrm{m})$ from the pia mater. The average scan distance was $35 \mu \mathrm{m}$ with a spatial resolution of $0.7 \mu \mathrm{m}$ per pixel, temporal resolution of 2 msec per scan, and duration of 128 seconds. Tracks of nonfluorescent RBCs appear as dark stripes and labeled plasma as bright stripes. The slope of the alternating dark and light stripes is proportional to RBC velocity (Fig. 2D). ${ }^{26}$ Multiple records were taken from the same vessel, and mean microvessel RBC velocity and standard error of the mean were calculated. All vessels in an imaging volume $(500 \times 500 \times 200 \mu \mathrm{m}, \mathrm{XYZ})$ were scanned, measuring the diameter of each vessel. Capillary selection was based on tortuosity, degree of branching, and diameters ranging from 3 to $8 \mu \mathrm{m} .{ }^{17,20,21,34,51}$ Precapillary arterioles were differentiated by morphology and RBC flow velocity and range in diameter from 11 to $50 \mu \mathrm{m} .{ }^{26}$ With NIH ImageJ in offline analysis, 3D anatomy of the vasculature in a region of interest was reconstructed from planar images obtained at successive focal depths in the cortex (XYZ-stack).

Nicotinamide adenine dinucleotide autofluorescence was emitted at a 740-nm center wavelength and filtered at $425-475 \mathrm{~nm} .^{6,7}$ Twenty planar scans of fluorescence intensity were obtained in $10-\mu \mathrm{m}$ steps starting from the pia matter at each imaging session. In offline analyses, average intensity was calculated from the maximal intensity projection. 


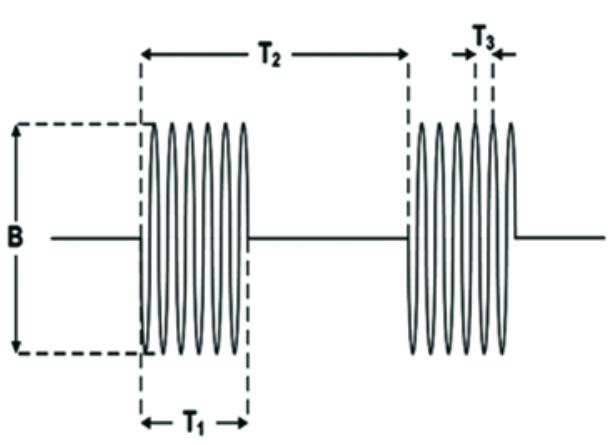

A
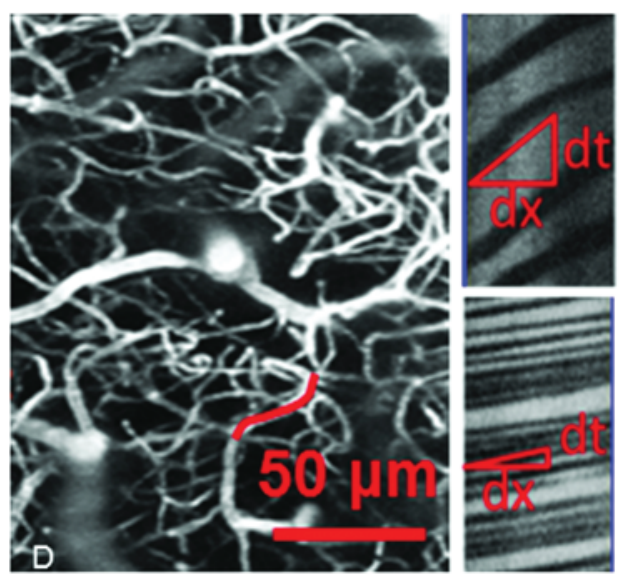

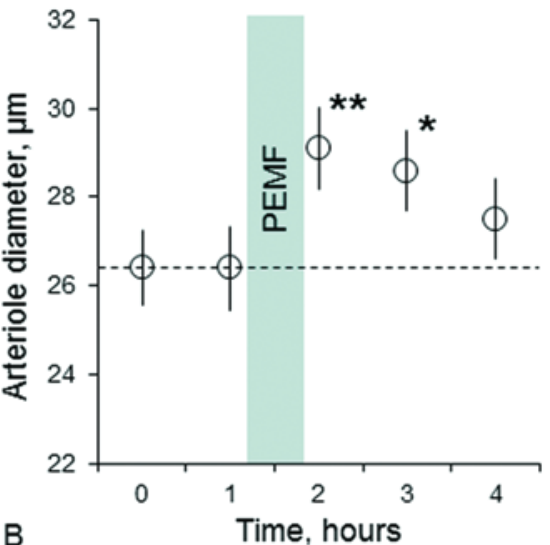

B

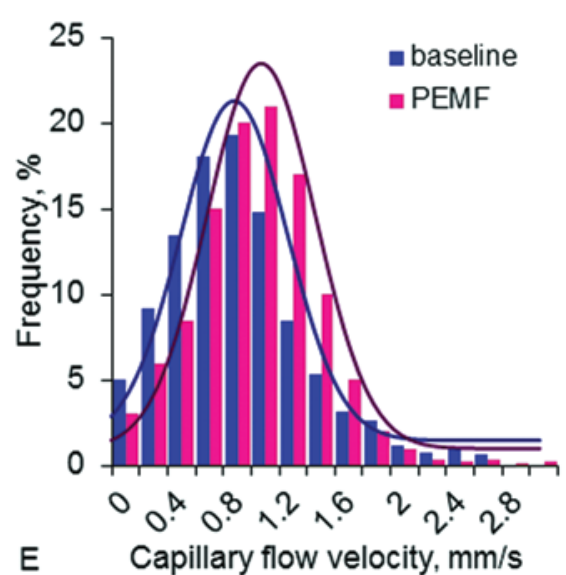

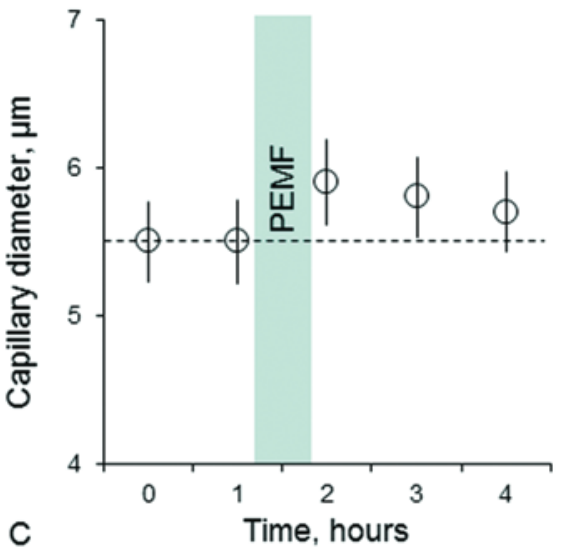

FIG. 2. Pulsed electromagnetic field treatment dilates cerebral arterioles and increases microvascular flow. A: The PEMF signal configuration: $\mathrm{T}_{1}, 3-\mathrm{msec}$ burst pulses; $1 / \mathrm{T}_{2}, 5 \mathrm{~Hz}$ at 2 bursts per second; $1 / \mathrm{T}_{3}, 27.12-\mathrm{MHz}$ carrier; $\mathrm{B}, 225 \mathrm{mV} / 9 \mu \mathrm{T}$ peak induced electromagnetic field. B: Time series plot shows the time course of the increase in arteriolar diameter (10-30 $\mu \mathrm{m})$ from $26.4 \pm 0.95$ $\mu \mathrm{m}$ before to a peak of $29.1 \pm 0.91 \mu \mathrm{m}$ after PEMF treatment. Diameters gradually returned to a baseline during 3 hours. C: Time series plot of average capillary diameters $(3-8 \mu \mathrm{m})$ shows insignificant dilation after PEMF treatment, returning to a baseline during 3 hours, following the arterioles pattern. D: Maximum intensity projection of a region from which microvascular flow was recorded (left, 20 planar scans acquired every $10 \mu \mathrm{m}$ from the brain surface). Line-scan data (upper right) for blood flow velocities in the capillary outlined in red in the left panel, indicating RBC flow velocity increase (lower right) after PEMF treatment. The slope of the stripes inversely reflects RBC flow velocity. E: Frequency histograms and gaussian fit show that PEMF treatment increased RBC flow velocity in capillaries $(3-8 \mu \mathrm{m})$ in the rat cortex in comparison with baseline. F: Time series plot shows an increase by $5.5 \%$ $\pm 1.3 \%$ in the average RBC flow velocity in capillaries after PEMF treatment compared with baseline. Capillary RBC flow velocity gradually returned to a baseline during 3 hours. Data are normalized to a baseline. For all time series plots: values represent the mean \pm SEM; 11 rats; ${ }^{* *} p<0.01,{ }^{*} p<0.05$. Dashed black line represents time control values. Figure is available in color online only.

Cortical Doppler flux was measured using a singlefiber, 0.8-mm-diameter surface Doppler probe (DRT4, Moor Instruments) secured at the juncture of the suture of the lateral parietal and temporal bones approximately 3 $\mathrm{mm}$ below and ipsilateral to the cranial window over the parietal cortex, through a small nonpenetrating thinnedskull bur hole. ${ }^{6,7}$

\section{Statistical Analysis}

Statistical analyses were performed using the Student t-test or the Kolmogorov-Smirnov test where appropriate. Differences between groups were determined using 2-way ANOVA for multiple comparisons and post hoc testing using the Mann-Whitney U-test. Bonferroni's multiplecomparison test was used for post hoc analysis, where the effects of different groups were compared. Significance level was preset to $\mathrm{p}<0.05$ except where Bonferroni correction indicated otherwise. Data are presented as the mean \pm standard error of the mean.

\section{Results}

\section{Dilation of Cerebral Arterioles and Increases in Microvascular Blood Flow}

Diameters of arterioles and capillaries in the volume of view $(500 \times 500 \times 300 \mu \mathrm{m})$ were measured at all experimental points, and averages were calculated. Pulsed electromagnetic field treatment dilated arterioles, with an increase in average diameter from a baseline of $26.4 \pm$ $0.84 \mu \mathrm{m}$ to $29.1 \pm 0.91 \mu \mathrm{m}$, which gradually returned to $27.5 \pm 0.90 \mu \mathrm{m}$, not significantly different from baseline after 3 hours (Fig. 2B and Table 1; 11 rats, $\mathrm{p}<0.01$ ). In capillaries, the dilatory effect of PEMF was notable but 
TABLE 1. Measured variables in healthy rats*

\begin{tabular}{|c|c|c|c|c|c|c|}
\hline Variable & Group & Baseline I & Baseline II or L-NAME & Post-PEMF, $0 \mathrm{Hr}$ & Post-PEMF, $1 \mathrm{Hr}$ & Post-PEMF, $2 \mathrm{Hrs}$ \\
\hline \multirow{3}{*}{$\begin{array}{r}\text { Average arteriole } \\
\text { diameter }(\mu \mathrm{m})\end{array}$} & Time control & $25.9 \pm 0.96$ & $26.0 \pm 0.94$ & $25.9 \pm 0.95$ & $26.1 \pm 0.90$ & $25.9 \pm 0.92$ \\
\hline & PEMF & $26.4 \pm 0.84$ & $26.4 \pm 0.95$ & $29.1 \pm 0.91 \dagger$ & $28.6 \pm 0.89 \ddagger$ & $27.5 \pm 0.90$ \\
\hline & L-NAME + PEMF & $25.8 \pm 0.87$ & $24.1 \pm 0.94 \S$ & $24.0 \pm 0.91$ & $24.2 \pm 0.89$ & $23.9 \pm 0.90$ \\
\hline \multirow{3}{*}{$\begin{array}{l}\text { Average capillary } \\
\text { diameter ( } \mu \mathrm{m})\end{array}$} & Time control & $5.65 \pm 0.31$ & $5.62 \pm 0.30$ & $5.67 \pm 0.32$ & $5.66 \pm 0.29$ & $5.65 \pm 0.33$ \\
\hline & PEMF & $5.51 \pm 0.27$ & $5.50 \pm 0.28$ & $5.92 \pm 0.29$ & $5.81 \pm 0.27$ & $5.74 \pm 0.28$ \\
\hline & L-NAME + PEMF & $5.72 \pm 0.36$ & $5.68 \pm 0.34$ & $5.71 \pm 0.30$ & $5.72 \pm 0.33$ & $5.70 \pm 0.29$ \\
\hline \multirow{3}{*}{$\begin{array}{l}\text { RBC flow velocity } \\
\text { (\% baseline) }\end{array}$} & Time control & $100.0 \pm 0.8$ & $100.4 \pm 1.0$ & $100.9 \pm 1.1$ & $98.1 \pm 1.5$ & $99.5 \pm 1.2$ \\
\hline & PEMF & $100.1 \pm 1.7$ & $100.5 \pm 1.8$ & $105.5 \pm 1.3 \dagger$ & $104.4 \pm 2.1 \ddagger$ & $102.8 \pm 1.9$ \\
\hline & L-NAME + PEMF & $100.0 \pm 1.8$ & $97.5 \pm 1.9 \pi$ & $97.9 \pm 1.8$ & $97.0 \pm 2.0$ & $97.8 \pm 2.1$ \\
\hline \multirow[t]{3}{*}{ NADH ( $\%$ baseline) } & Time control & $100.0 \pm 1.4$ & $99.8 \pm 1.6$ & $100.3 \pm 2.5$ & $100.2 \pm 2.2$ & $99.9 \pm 2.4$ \\
\hline & PEMF & $100.0 \pm 1.7$ & $100.3 \pm 1.8$ & $94.7 \pm 1.6 \dagger$ & $96.2 \pm 2.2 \ddagger$ & $97.4 \pm 1.9$ \\
\hline & L-NAME + PEMF & $100.0 \pm 1.8$ & $102.4 \pm 1.8^{* *}$ & $102.3 \pm 1.7$ & $102.4 \pm 2.1$ & $102.5 \pm 2.0$ \\
\hline \multirow{3}{*}{$\begin{array}{l}\text { Doppler flux } \\
\text { (\% baseline) }\end{array}$} & Time control & $100.0 \pm 0.6$ & $98.8 \pm 0.8$ & $101.1 \pm 0.5$ & $100.1 \pm 0.5$ & $99.7 \pm 0.6$ \\
\hline & PEMF & $100.1 \pm 0.7$ & $99.7 \pm 0.8$ & $105.1 \pm 0.7 \dagger \dagger$ & $103.4 \pm 0.5$ & $102.3 \pm 0.6$ \\
\hline & L-NAME + PEMF & $100.0 \pm 0.9$ & $96.1 \pm 0.9 \S \S$ & $97.3 \pm 0.8$ & $97.4 \pm 0.9$ & $98.2 \pm 0.7$ \\
\hline
\end{tabular}

* Values are expressed as the mean \pm standard error of the mean. Five rats were in the time control group, 11 in the PEMF group, and 7 in the L-NAME group.

$\dagger p<0.01$

$\ddagger p<0.05$.

$\S p<0.24$.

If $p<0.3$.

** $p<0.18$.

†† $p<0.09$

$\S \S p<0.11$.

insignificant and followed arteriolar diameter changes that returned to baseline during 3 hours after treatment (Fig. 2C; 11 rats). In the time control group, arterioles and capillary diameters were unchanged over 4 hours (Table 1). Arterioles are the primary site of vascular resistance and probably the primary target for NO-induced vasodilation. Capillary walls do not have smooth muscle and are therefore not susceptible to NO vasodilatory effects. However, dilation could be a function of increased wall shear stress due to increased blood volume flow resulting in increased transmural pressure and enlargement of the capillaries. ${ }^{24}$

Red blood cell flow velocities were measured for each capillary in the imaged volume $(500 \times 500 \times 300 \mu \mathrm{m})$ at all experimental points, and frequency histograms were plotted. Flow velocity-frequency histograms and gaussian plots for capillaries $(3-8 \mu \mathrm{m})$ in a rat brain showed that normal RBC velocity ranged from 0.14 to $3.15 \mathrm{~mm} /$ second with a normal distribution (Fig. 2E). After PEMF treatment, the frequency histogram and gaussian plot showed a shift in capillary flow velocities to higher velocities (Fig. 2E). When averaged and normalized to baseline, capillary blood flow velocities increased to $105.5 \% \pm$ 1.3\% after PEMF treatment (Table 1 and Fig. 2F; 11 rats, $\mathrm{p}<0.01)$. Capillary RBC flow velocity gradually fell to $102.8 \% \pm 1.9 \%$ over 3 hours after PEMF treatment, which was not significantly different from baseline. In the time control group, significant changes were not observed over the 4 hours monitored.

\section{Enhanced Tissue Oxygenation After PEMF Treatment}

The coenzyme NADH is the primary electron donor in oxidative phosphorylation, and its redox state reflects mitochondrial activity, which depends on tissue oxygenation. Note that NADH is fluorescent, whereas oxidized NAD+ is not; therefore, NADH autofluorescence is a sensitive indicator of cellular oxidation ${ }^{8}$ and was used here to evaluate tissue oxygenation. ${ }^{6,754}$ The NADH autofluorescence was evenly distributed in the rat parietal cortex, showing a gradual increase in intensity with distance from the microvessels (Table 1 and Fig. 3A) because of the oxygen gradient. ${ }^{54}$ The PEMF treatment decreased NADH autofluorescence to $94.7 \% \pm 1.6 \%$ of baseline, reflecting improved tissue oxygenation (Fig. 3B and C; 11 rats, $\mathrm{p}$ $<0.05$ ). The NADH concentration gradually returned to $97.4 \% \pm 1.9 \%$ of baseline over 3 hours after PEMF treatment, correlating with the changes in microvascular diameter and RBC flow velocity. In the time control group, NADH fluorescence was unaltered over the 4 hours.

\section{Blocking the Effects of PEMF Treatment on the Cortical Microcirculation and Metabolism by NOS Inhibition With L-NAME}

Nitric oxide synthase inhibition with L-NAME was used to evaluate the role of NO in modulating the effects of PEMF on the microcirculation of the brain. The inhibition of NOS prevented the change in arteriolar diameters after PEMF stimulation (Table 1 and Fig. 4A; 7 rats). Similarly, capillary RBC flow velocity and tissue 

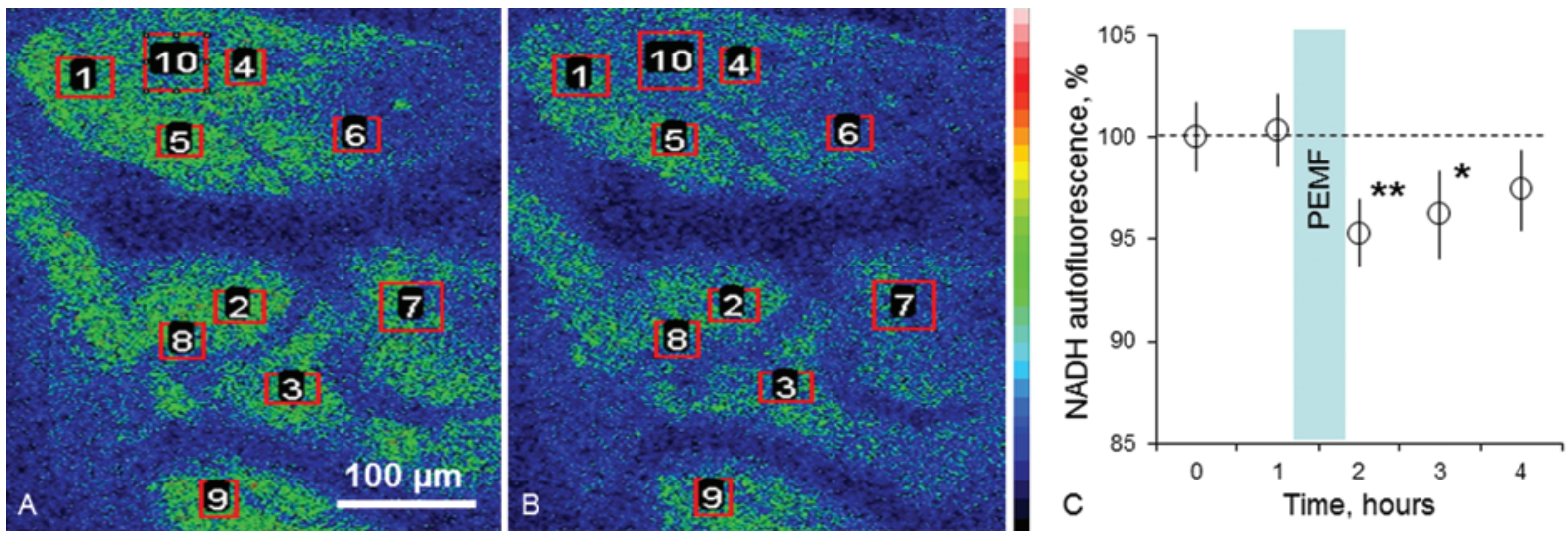

FIG. 3. Pulsed electromagnetic field-induced enhancement of cerebral microvascular flow increases tissue oxygenation. In vivo 2PLSM images of NADH autofluorescence in normal rat cortex at baseline (A) and after PEMF treatment (B) with regions of interest representing a decrease in NADH autofluorescence. Time series plots (C) from the ROls presented in panels $A$ and $B$, showing decreased NADH by $5.3 \% \pm 1.6 \%$ after PEMF treatment, reflecting improved tissue oxygenation. The NADH gradually returned to baseline over 3 hours, correlating with changes in arteriolar diameters and capillary RBC flow velocity. Values represent the mean \pm SEM; 11 rats; ${ }^{* *} p<0.01,{ }^{*} p<0.05$. Data are presented as a percentage of baseline. Dashed black line represents time control values. Figure is available in color online only.

oxygenation, reflected by NADH autofluorescence, were unchanged after PEMF treatment when NOS was blocked by L-NAME (Fig. 4B and C). These data show that the effects of PEMF on cerebral microcirculation and oxygenation are modulated by NO.

Interestingly, L-NAME inhibition of NOS caused arteriolar constriction from $25.8 \pm 0.87 \mu \mathrm{m}$ at a baseline to $24.1 \pm 0.94 \mu \mathrm{m}$ probably due to baseline NO depletion (Table 1 and Fig. 4A; 7 rats, $p<0.24$ ). Arteriolar constriction led to reduced blood volume flow and reduced capillary $\mathrm{RBC}$ velocity to $97.5 \% \pm 1.9 \%$ of normal (Fig. 4B; $\mathrm{p}$ $<0.3$ ). The reduction in microvascular perfusion led to an increase in NADH autofluorescence to $102.4 \% \pm 1.8 \%$ of baseline, reflecting decreased tissue oxygenation (Fig. 4C; $\mathrm{p}<0.18)$. However, these changes were not statistically significant.

\section{Discussion}

High-frequency PEMF treatment with the SofPulse device in the brain of healthy anesthetized rats dilated arterioles (10-30 um), increased RBC flow velocity, and decreased NADH, indicating improved tissue oxygenation. The vasodilatory effect of PEMF persisted for 3 hours then gradually returned to baseline. Our studies show that the blockade of NO synthesis abolished the effects of PEMF on the cerebrovasculature, supporting the hypothesis that PEMF effects are mediated by NO. These results support
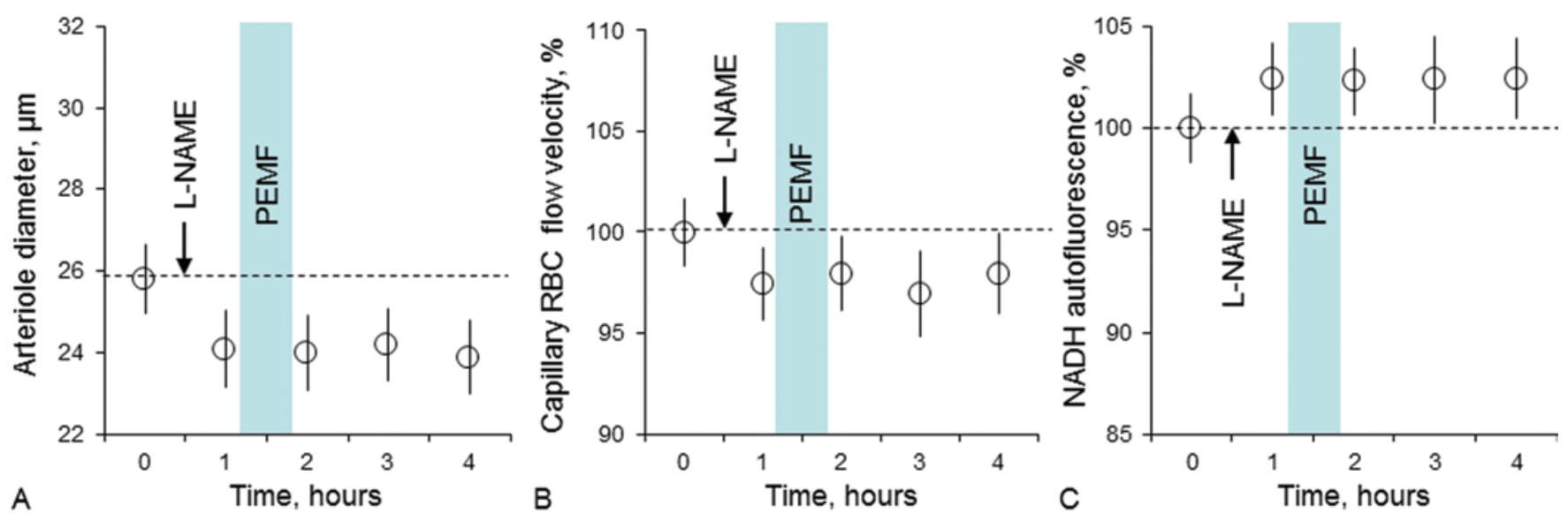

FIG. 4. The inhibition of NOS via L-NAME obliterates the effects of PEMF on cerebrovascular flow and metabolism. A: Time series plot shows that NOS inhibition ceases dilation of arterioles (10-30 $\mu \mathrm{m})$ by PEMF treatment. Note that the intravenous injection of L-NAME causes steady constriction, reflecting NO depletion. B: Time series plot shows no changes in RBC flow velocity in capillaries after PEMF treatment during NOS inhibition. Note that L-NAME induced a decrease in capillary blood flow due to arteriolar constriction. C: Time series plot shows no change in NADH autofluorescence after PEMF treatment during NOS inhibition, reflecting no effect on tissue oxygenation. Note that L-NAME increased NADH because of reduced capillary perfusion and decreased tissue oxygenation. For all time series plots: values represent the mean \pm SEM; 7 rats; data are presented as a percentage of baseline. Dashed black line represents time control values. Figure is available in color online only. 
findings in some studies $\mathrm{s}^{9,33,36,41-43}$ while contradicting others. $^{3,25}$ The reason for this difference may be attributable to the use of various tissues and varying PEMF treatment parameters.

Similar to the effects of PEMF exposure on NO, the effects of exposure on blood flow also vary and could also depend on PEMF treatment parameters. The microvascular response could also depend on the tissue studied, which makes it difficult to compare our results with those of other studies since this is the first application to the brain. Few studies using positron emission tomography on healthy humans, addressing concern over the safety of cellular phone use, have shown either an increase in global cerebral blood flow ${ }^{19}$ or no effect. ${ }^{16}$ However, the parameters of the cell phone electromagnetic field are very different from what we used $(900 \mathrm{MHz}$ with a $217-\mathrm{Hz}$ pulse rate in cell phones vs $27.12 \mathrm{MHz}$ with a $5-\mathrm{Hz}$ pulse rate in SofPulse) and hardly comparable, as electromagnetic fields in the SofPulse range pass unaffected through tissue types while those above that range are increasingly attenuated.

The effects of PEMF on microvascular vasodilation and flow in the healthy rat brain were statistically significant but relatively small. However, in the ischemic or injured brain, the effects of PEMF on microvascular flow could be amplified as a result of a decrease in vascular wall shear stress, which could be counteracted synergistically by an increase in microvascular wall shear stress provided by vasodilation and increased microvascular flow via PEMF. The vascular wall is highly sensitive to the hydrodynamic forces exerted on the endothelium by flowing blood, which affects the endothelial phenotype by regulating the activity of flow-sensitive proteins. ${ }^{56}$ The resultant increase in vascular wall shear stress would also improve circulation by inhibiting leukocyte adhesion to the endothelial wall and counter the production of apoptotic mechanisms and inflammatory mediators. ${ }^{46,58,59}$ Thus, whereas the effects on the cerebrovasodilatory and inflammatory response in the healthy brain may be small, the effects in the injured brain could be amplified. The effect of PEMF in improving wound healing supports the notion that the PEMF treatment effects may be amplified

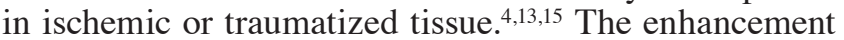
of microvascular flow, increase of vascular wall shear stress, and improved tissue oxygenation could be a result of several mechanisms leading to the decrease in ischemic infarction reported in previous studies..$^{14,39}$

The increase in cerebral perfusion was not detected by the $0.8-\mathrm{mm}$-diameter Doppler flow probe with a tissue volume of about $0.8 \mathrm{~mm}^{3}$ (Table 1), which is probably attributable to volume averaging of tissue perfusion, as reported by Jones et al. ${ }^{23}$ The smaller the tissue volume sampled, the greater the variability in the pattern of perfusion. Conversely, the greater the volume of tissue sampled, the more homogenous the patterns of blood flow. Thus, at the microvascular level of 3-30 um diameter, the heterogeneity of perfusion is clearly demonstrable, showing some microvasculature with increased RBC flow velocity. This might be a partial reason for contradictory results in previous studies using Doppler flow probes. Using 2PLSM, we were able to differentiate diameter and blood flow changes in different microvascular compartments and to track them in each individual microvessel in an imaged volume of $500 \times 500 \times 300 \mu \mathrm{m}$.

\section{Conclusions}

Our observations show that PEMF induce arteriolar dilation by an NO-dependent mechanism. Vasodilation leads to an increase in cerebral microvascular blood flow and, as a result, improved tissue oxygenation that persists for 3 hours. Our studies explain a possible mechanism of action of PEMF in wound healing and suggest that PEMF may be an effective treatment strategy after severe traumatic and ischemic brain insults.

\section{Acknowledgments}

We thank Dr. Arthur Pilla for his invaluable intellectual input and Anthony Gravagne, Prototype Machinist from the Machine Shops at the Department of Physics and Astronomy, University of New Mexico, for designing and manufacturing the non-magnetic plastic stereotactic head frame for imaging. Data were obtained using the Optical Core of the Biomedical Research and Integrative Neuroimaging Center at the University of New Mexico, supported by NIH CoBRE 8P30GM103400.

\section{References}

1. Aaron RK, Ciombor DM, Simon BJ: Treatment of nonunions with electric and electromagnetic fields. Clin Orthop Relat Res (419):21-29, 2004

2. Akai M, Hayashi K: Effect of electrical stimulation on musculoskeletal systems; a meta-analysis of controlled clinical trials. Bioelectromagnetics 23:132-143, 2002

3. Akdag MZ, Bilgin MH, Dasdag S, Tumer C: Alteration of nitric oxide production in rats exposed to a prolonged, extremely low-frequency magnetic field. Electromagn Biol Med 26:99-106, 2007

4. Assiotis A, Sachinis NP, Chalidis BE: Pulsed electromagnetic fields for the treatment of tibial delayed unions and nonunions. A prospective clinical study and review of the literature. J Orthop Surg 7:24, 2012

5. Baptista AF, Goes BT, Menezes D, Gomes FC, Zugaib J, Stipursky J, et al: PEMF fails to enhance nerve regeneration after sciatic nerve crush lesion. J Peripher Nerv Syst 14:285-293, 2009

6. Bragin DE, Bush RC, Müller WS, Nemoto EM: High intracranial pressure effects on cerebral cortical microvascular flow in rats. J Neurotrauma 28:775-785, 2011

7. Bragin DE, Bush RC, Nemoto EM: Effect of cerebral perfusion pressure on cerebral cortical microvascular shunting at high intracranial pressure in rats. Stroke 44:177-181, 2013

8. Chance B, Cohen P, Jobsis F, Schoener B: Intracellular oxidation-reduction states in vivo. Science 137:499-508, 1962

9. Diniz P, Soejima K, Ito G: Nitric oxide mediates the effects of pulsed electromagnetic field stimulation on the osteoblast proliferation and differentiation. Nitric Oxide 7:18-23, 2002

10. Famm K, Litt B, Tracey KJ, Boyden ES, Slaoui M: Drug discovery: a jump-start for electroceuticals. Nature 496:159161,2013

11. Gilcreast DM, Stotts NA, Froelicher ES, Baker LL, Moss KM: Effect of electrical stimulation on foot skin perfusion in persons with or at risk for diabetic foot ulcers. Wound Repair Regen 6:434-441, 1998

12. Gossling HR, Bernstein RA, Abbott J: Treatment of ununited tibial fractures: a comparison of surgery and pulsed electromagnetic fields (PEMF). Orthopedics 15:711-719, 1992

13. Goudarzi I, Hajizadeh S, Salmani ME, Abrari K: Pulsed 
electromagnetic fields accelerate wound healing in the skin of diabetic rats. Bioelectromagnetics 31:318-323, 2010

14. Grant G, Cadossi R, Steinberg G: Protection against focal cerebral ischemia following exposure to a pulsed electromagnetic field. Bioelectromagnetics 15:205-216, 1994

15. Gupta A, Taly AB, Srivastava A, Kumar S, Thyloth M: Efficacy of pulsed electromagnetic field therapy in healing of pressure ulcers: a randomized control trial. Neurol India 57:622-626, 2009

16. Haarala C, Aalto S, Hautzel H, Julkunen L, Rinne JO, Laine M, et al: Effects of a $902 \mathrm{MHz}$ mobile phone on cerebral blood flow in humans: a PET study. Neuroreport 14:20192023, 2003

17. Hauck EF, Apostel S, Hoffmann JF, Heimann A, Kempski O: Capillary flow and diameter changes during reperfusion after global cerebral ischemia studied by intravital video microscopy. J Cereb Blood Flow Metab 24:383-391, 2004

18. Hedén P, Pilla AA: Effects of pulsed electromagnetic fields on postoperative pain: a double-blind randomized pilot study in breast augmentation patients. Aesthetic Plast Surg 32:660-666, 2008

19. Huber R, Treyer V, Borbély AA, Schuderer J, Gottselig JM, Landolt HP, et al: Electromagnetic fields, such as those from mobile phones, alter regional cerebral blood flow and sleep and waking EEG. J Sleep Res 11:289-295, 2002

20. Hudetz AG, Fehér G, Kampine JP: Heterogeneous autoregulation of cerebrocortical capillary flow: evidence for functional thoroughfare channels? Microvasc Res 51:131-136, 1996

21. Hudetz AG, Fehér G, Weigle CG, Knuese DE, Kampine JP: Video microscopy of cerebrocortical capillary flow: response to hypotension and intracranial hypertension. Am J Physiol 268:H2202-H2210, 1995

22. Ito H, Bassett CA: Effect of weak, pulsing electromagnetic fields on neural regeneration in the rat. Clin Orthop Relat Res (181):283-290, 1983

23. Jones SC, Radinsky CR, Furlan AJ, Chyatte D, Qu Y, Easley $\mathrm{KA}$, et al: Variability in the magnitude of the cerebral blood flow response and the shape of the cerebral blood flow: pressure autoregulation curve during hypotension in normal rats. Anesthesiology 97:488-496, 2002 (Erratum in Anesthesiology 97:1332, 2002)

24. Kamiya A, Togawa T: Adaptive regulation of wall shear stress to flow change in the canine carotid artery. Am J Physiol 239:H14-H21, 1980

25. Kim SS, Shin HJ, Eom DW, Huh JR, Woo Y, Kim H, et al: Enhanced expression of neuronal nitric oxide synthase and phospholipase $\mathrm{C}-\gamma 1$ in regenerating murine neuronal cells by pulsed electromagnetic field. Exp Mol Med 34:53-59, 2002

26. Kleinfeld D, Mitra PP, Helmchen F, Denk W: Fluctuations and stimulus-induced changes in blood flow observed in individual capillaries in layers 2 through 4 of rat neocortex. Proc Natl Acad Sci U S A 95:15741-15746, 1998

27. Mayrovitz HN, Larsen PB: Effects of pulsed electromagnetic fields on skin microvascular blood perfusion. Wounds 4:197-202, 1992

28. Mayrovitz HN, Larsen PB: A preliminary study to evaluate the effect of pulsed radio frequency field treatment on lower extremity peri-ulcer skin microcirculation of diabetic patients. Wounds 7:90-93, 1995

29. McKay JC, Corbacio M, Tyml K, Prato FS, Thomas AW: Extremely low frequency pulsed electromagnetic field designed for antinociception does not affect microvascular responsiveness to the vasodilator acetylcholine. Bioelectromagnetics 31:64-76, 2010

30. McKay JC, Prato FS, Thomas AW: A literature review: the effects of magnetic field exposure on blood flow and blood vessels in the microvasculature. Bioelectromagnetics 28:8198, 2007
31. Midura RJ, Ibiwoye MO, Powell KA, Sakai Y, Doehring T, Grabiner MD, et al: Pulsed electromagnetic field treatments enhance the healing of fibular osteotomies. J Orthop Res 23:1035-1046, 2005

32. Miura M, Okada J: Non-thermal vasodilatation by radio frequency burst-type electromagnetic field radiation in the frog. J Physiol 435:257-273, 1991

33. Miura M, Takayama K, Okada J: Increase in nitric oxide and cyclic GMP of rat cerebellum by radio frequency burst-type electromagnetic field radiation. J Physiol 461:513-524, 1993

34. Motti ED, Imhof HG, Yaşargil MG: The terminal vascular bed in the superficial cortex of the rat. An SEM study of corrosion casts. J Neurosurg 65:834-846, 1986

35. Nelson FR, Zvirbulis R, Pilla AA: Non-invasive electromagnetic field therapy produces rapid and substantial pain reduction in early knee osteoarthritis: a randomized double-blind pilot study. Rheumatol Int 33:2169-2173, 2013

36. Noda Y, Mori A, Liburdy RP, Packer L: Pulsed magnetic fields enhance nitric oxide synthase activity in rat cerebellum. Pathophysiology 7:127-130, 2000

37. Pan Y, Dong Y, Hou W, Ji Z, Zhi K, Yin Z, et al: Effects of PEMF on microcirculation and angiogenesis in a model of acute hindlimb ischemia in diabetic rats. Bioelectromagnetics 34:180-188, 2013

38. Patruno A, Amerio P, Pesce M, Vianale G, Di Luzio S, Tulli A, et al: Extremely low frequency electromagnetic fields modulate expression of inducible nitric oxide synthase, endothelial nitric oxide synthase and cyclooxygenase- 2 in the human keratinocyte cell line HaCat: potential therapeutic effects in wound healing. Br J Dermatol 162:258-266, 2010

39. Pena-Philippides JC, Yang Y, Bragina O, Hagberg S, Nemoto E, Roitbak T: Effect of pulsed electromagnetic field (PEMF) on infarct size and inflammation after cerebral ischemia in mice. Transl Stroke Res 5:491-500, 2014

40. Pennington GM, Danley DL, Sumko MH, Bucknell A, Nelson JH: Pulsed, non-thermal, high-frequency electromagnetic energy (DIAPULSE) in the treatment of grade I and grade II ankle sprains. Mil Med 158:101-104, 1993

41. Pilla A, Fitzsimmons R, Muehsam D, Wu J, Rohde C, Casper $\mathrm{D}$ : Electromagnetic fields as first messenger in biological signaling: application to calmodulin-dependent signaling in tissue repair. Biochim Biophys Acta 1810:1236-1245, 2011

42. Pilla AA: Electromagnetic fields instantaneously modulate nitric oxide signaling in challenged biological systems. Biochem Biophys Res Commun 426:330-333, 2012

43. Pilla AA: Mechanisms and therapeutic applications of timevarying and static magnetic fields, in Barnes FS, Greenebaum, B (eds): Biological and Medical Aspects of Electromagnetic Fields. Boca Raton, FL: CRC Press, 2006, pp 351-412

44. Pilla AA: Nonthermal electromagnetic fields: from first messenger to therapeutic applications. Electromagn Biol Med 32:123-136, 2013

45. Rasouli J, Lekhraj R, White NM, Flamm ES, Pilla AA, Strauch B, et al: Attenuation of interleukin-1beta by pulsed electromagnetic fields after traumatic brain injury. Neurosci Lett 519:4-8, 2012

46. Resnick N, Yahav H, Shay-Salit A, Shushy M, Schubert S, Zilberman LC, et al: Fluid shear stress and the vascular endothelium: for better and for worse. Prog Biophys Mol Biol 81:177-199, 2003

47. Rohde C, Chiang A, Adipoju O, Casper D, Pilla AA: Effects of pulsed electromagnetic fields on interleukin-1 beta and postoperative pain: a double-blind, placebo-controlled, pilot study in breast reduction patients. Plast Reconstr Surg 125:1620-1629, 2010

48. Sandyk R: Alzheimer's disease: improvement of visual memory and visuoconstructive performance by treatment with picotesla range magnetic fields. Int J Neurosci 76:185-225, 1994 
49. Sandyk R: Brief communication: electromagnetic fields improve visuospatial performance and reverse agraphia in a parkinsonian patient. Int J Neurosci 87:209-217, 1996

50. Schuhfried O, Vacariu G, Rochowanski H, Serek M, FialkaMoser V: The effects of low-dosed and high-dosed lowfrequency electromagnetic fields on microcirculation and skin temperature in healthy subjects. Int J Sports Med 26:886-890, 2005

51. Seylaz J, Charbonné R, Nanri K, Von Euw D, Borredon J, Kacem K, et al: Dynamic in vivo measurement of erythrocyte velocity and flow in capillaries and of microvessel diameter in the rat brain by confocal laser microscopy. J Cereb Blood Flow Metab 19:863-870, 1999

52. Sisken BF, Kanje M, Lundborg G, Kurtz W: Pulsed electromagnetic fields stimulate nerve regeneration in vitro and in vivo. Restor Neurol Neurosci 1:303-309, 1990

53. Smith TL, Wong-Gibbons D, Maultsby J: Microcirculatory effects of pulsed electromagnetic fields. J Orthop Res 22:80-84, 2004

54. Takano T, Tian GF, Peng W, Lou N, Lovatt D, Hansen AJ, et al: Cortical spreading depression causes and coincides with tissue hypoxia. Nat Neurosci 10:754-762, 2007

55. Tepper OM, Callaghan MJ, Chang EI, Galiano RD, Bhatt $\mathrm{KA}$, Baharestani S, et al: Electromagnetic fields increase in vitro and in vivo angiogenesis through endothelial release of FGF-2. FASEB J 18:1231-1233, 2004

56. Topper JN, Gimbrone MA Jr: Blood flow and vascular gene expression: fluid shear stress as a modulator of endothelial phenotype. Mol Med Today 5:40-46, 1999

57. Ueno S, Lövsund P, Oberg PA: Effects of alternating magnetic fields and low-frequency electric currents on human skin blood flow. Med Biol Eng Comput 24:57-61, 1986

58. World CJ, Garin G, Berk B: Vascular shear stress and activation of inflammatory genes. Curr Atheroscler Rep 8:240244, 2006
59. Yamawaki H, Pan S, Lee RT, Berk BC: Fluid shear stress inhibits vascular inflammation by decreasing thioredoxin-interacting protein in endothelial cells. J Clin Invest 115:733738,2005

60. Yuan Y, Wei L, Li F, Guo W, Li W, Luan R, et al: Pulsed magnetic field induces angiogenesis and improves cardiac function of surgically induced infarcted myocardium in Sprague-Dawley rats. Cardiology 117:57-63, 2010

\section{Author Contributions}

Conception and design: Bragin, Nemoto. Acquisition of data: Bragin, Statom. Analysis and interpretation of data: Bragin, Statom, Nemoto. Drafting the article: Bragin. Critically revising the article: all authors. Reviewed submitted version of manuscript: all authors. Approved the final version of the manuscript on behalf of all authors: Bragin. Statistical analysis: Statom. Administrative/technical/material support: Hagberg. Study supervision: Nemoto. Performed surgery: Statom.

\section{Supplemental Information}

Previous Presentation

The data described in this paper were presented in part as a poster at the International Stroke Conference held in Honolulu, Hawaii, on February 6-8, 2013.

\section{Correspondence}

Denis E. Bragin, 1 University of New Mexico, Department of Neurosurgery, MSC10 5615, Albuquerque, NM 87131. email: dbragin@salud.unm.edu. 